UDK: 331.4::8

Izvorni naučni rad

Dr. sc. Hatidže Burnić, docent

Univerzitet u Bihaću

Islamski pedagoški fakultet

hatidze_b@hotmail.com

Anita Mujkić, asistent

Univerzitet u Bihaću

Islamski pedagoški fakultet

anita_ramulic@yahoo.com

\title{
ODNOS VERBALNE, NEVERBALNE I PARAVERBALNE KOMUNIKACIJE U RADNOJ SREDINI
}

\section{Sažetak}

$U$ radu će se prikazati osnovne osobine verbalne, neverbalne $i$ paraverbalne komunikacije. Nakon prikaza navedenih elemenata sa posebnim aspektom na paralingvistička sredstava, slijedi opis verbalne, neverbalne $i$ paraverbalne komunikacije $i$ njihov odnos u kontekstu radne atmosfere, te važnost adekvatnog korištenja navedenih elemenata u komunikacijskom procesu.

Ključne riječi: Komunikacija, neverbalna, verbalna, paraverbalna komunikacija, paralingvistička sredstva

\section{UVOD}

Komunikacija predstavlja osnov za obavljanje poslova pa je samim tim jedan od najvažnijih faktora u radnoj sredini.Verbalna komunikacija je temelj za realizaciju poslovnih ideja u modernom kancelarijskom poslovanju u čemu se ogleda i njen značaj. Neverbalna komunikacija je važan dio komunikacijskog procesa, mada većina teoretičara ističe verbalnu komunikaciju jer je ona sama po sebi sporazumijevanje, a pritom zanemaruju neverbalnu komunikaciju kao nešto sporedno. Ukoliko dođu u koliziju verbalna, neverbalna i paraverbalna komunikacija, postoji velika vjerojatnoća da ćemo sagovorniku poslati poruku koju ne želimo. U radu će se prikazati načini usklađivanja navedenih elemenata u svrhu stvaranja pozitivne radne atmosfere. 


\section{Odnos verbalne, neverbalne i paraverbalne komunikacije u radnoj sredini}

U profesionalnoj komunikaciji na radnom mjestu među zaposlenicima odvija se interpersonalna komunikacija koja uključuje verbalnu, neverbalnu i paraverbalnu komunikaciju. U profesionalnoj komunikaciji verbalna komunikacija određuje se kao osnovna komunikacija koja mora biti jasno definisana, određena kontekstom $\mathrm{u}$ kojem se realizira te adekvatno shvaćena od strane sagovornika. ${ }^{1}$

$\mathrm{U}$ tom kontekstu neverbalna komunikacija je važna jer prenosi emocionalno stanje prilikom razgovora i jedan od najvažnijih elemenata zajedno sa paraverbalnom komunikacijom koja podrazumijeva način na koji izgovaramo riječi. U radnoj atmosferi najvažniji momenat je da navedeni oblici komunikacije ne dođu $\mathrm{u}$ koliziju kako bi poruka bila adekvatno prenesena. U govorničkim profesijama (advokatura, nastavnički poziv, menadžerski poslovi, sekretarski) najvažniji momenat je slaganje verbalnih, neverbalnih i paraverbalnih komponenti u komunikaciji jer odstupanje od navednog može dovesti do konfliktnih situacija. Stoga uposlenici moraju vješto vladati komunikacijskim vještinama. U kontekstu komunikacijskih vještina na radnom mjestu polazi se od nekoliko pravila kojih se moramo pridržavati kako bi ostavarili efikasniju komunikaciju i postigli željene ciljeve. Efikasna komunikacija podrazumijeva sinhroniziranje elemenata verbalne, neverbalne i paraverbalne komunikacije. Prilikom komuniciranja sa sagovornikom šaljemo veliki broj poruka, signala putem položaja našeg tijela, odnosno neverbalnom komunikacijom.

Položaj tijela jedan je od najvažnijih elemenata neverbalne komunikacije. Naime, ako nam nije ugodno, naše tijelo zauzima odbrambeni stav (npr. prekrižene ruke ili noge). Položaj tijela prilikom komunikacije odražava samopouzdanje osobe tako uspravan položaj tijela ukazuje na samopouzdanje, a opušten položaj tijela ukazuje na nelagodu i nedostatak samopouzdanja.

${ }^{1}$ Opširnije o problematici neverbalnog upravljanja konverzacijom te utjecajima neverbalnog ponašanja na konverzaciju vidjeti u: Kathleen $K$. Reardon, Interpersonalna komunikacija gdje se misli susreću, Alinea, Zagreb, 1998. godine, str. 101-104. 
Stoga navodimo nekoliko primjera adekvatnog ponašanja prilikom poslovnog sastanka (npr. prilikom poslovnog sastanka ako sjedimo na rubu stolice to jasno ukazuje da nam nije udobno i da želimo da sastanak što prije završi, stoga, ako ne želimo poslati ovakvu poruku, trebamo zauzeti drugačiji položaj tijela). Dobri poznavaoci komunikacijskih vještina mogu pročitati signale koji im šalju drugi ljudi prilikom komunikacije, a, također, svoje geste odnosno neverbalnu komunikaciju drže pod kontrolom (npr. dobri advokati i menadžeri koriste „tehniku ogledala“ kako bi zadobili povjerenje sagovornika i utjecali na stavove druge osobe). ${ }^{2}$

Jedan od najvažnijih elemenata neverbalne komunikacije su ruke jer 7\% komunikacije čini verbalni dio, $55 \%$ vizuelni dio, $38 \%$ vokalni (ton, brzina, jačina itd.). Ton našeg glasa kao osnovni paraverbalni element određuje stanje u kojem se sagovnik nalazi. Naime, ako ton glasa govori jedno, a facijalna ekspresija ukazuje na drugu komponentu, saradnja između sagovornika se teže uspostavlja. Istraživanja su pokazala da se emocije poput bijesa, mržnje i gađenje ogledaju na licu, a sreća, ponos i stid jasno vide kroz facijalnu ekspresiju. ${ }^{3}$

U profesionalnoj komunikaciji, veliku pažnju treba posvetiti paraverbalnim komponentama. Veoma je važno sniziti i usporiti ton glasa kako bismo bili optimistični, srdačni i osjećajniji. Sporiji govor je važan jer povećava poštovanje sagovornika, stoga, ovu vještinu treba vježbati. Gestikulacija je važna jer držanjem tijela sagovorniku dajemo poruku koju možda ne želimo posebno u radnoj atmosferi.

U radnoj sredini posebno je važan javni nastup i publici se obraćamo potpuno otvorenog držanja tijela gdje dajemo poruku da smo otvoreni i publika nas percipira na takav način ako su ruke ispred ili iza nas stvaramo nevidljivi zid između nas i publike. Naprimjer, možemo imati

2 ,Tehnika ogledala“ ne podrazumijeva samo preslikavanje govora tijela sagovornika nego se odvija suptilno (npr. na početku razgovora oni koriste niži ton glasa i nakon toga lagano ubrzavaju kako bi pratili da li ih sagovonik sluša, nakon toga lagano se naginju prema sagovorniku i ako se sagovornik naginje prema njima znači da ih on sluša dakle putem govora tijela posmatra reakciju druge strane).

3 Opširnije o problematici neverbalnog upravljanja konverzacijom te utjecajima neverbalnog ponašanja na konverzaciju vidjeti $u$ : Kathleen $K$. Reardon, Interpersonalna komunikacija gdje se misli susreću, Alinea, Zgreb, 1998. godine, str. 102. 
vrhunsku prezentaciju, važan projekat koji moramo prezentirati, ako našu prezentaciju ne prate određene geste, intonacija nećemo poslati poruku koju želimo. Naime, rukama oslikavamo našu prezentaciju, našim govorom tijela adekvatno pokrivamo prezentaciju. Gestikulacija mora biti upečatljiva, nećemo je koristiti često u toku izlaganja nego na mjestima koja želimo da istaknemo.

Najbolji govornici koriste veliki prostor kada izlažu kreću se slobodno i polagano, jer nagli pokreti i nervozno šetanje mogu biti kontraproduktivni. Najbolji govornici ne čitaju pripremljenu materiju, oni izlažu usmeno uz animiranje govora tijela. Također, treba voditi računa i o međusobnoj udaljenosti prilikom komunikacije; nedopustivo je uzurpiranje prostora druge osobe, lični prostor druge osobe je oko pola metra, ovu barijeru možemo preći samo kod bliskih prijatelja.

U kontekstu navedenog ističe se da je osmijeh važan element poslovne komunikacije istraživanje je pokazalo da izvinjenje dato uz osmijeh ima pozitivne efekte i može utjecati na izricanje blaže kazne. Stoga je važno da osmjehivanje, posebno u poslovnoj komunikaciji, bude važan dio repertoara jer takvim stavom nesvjesno utječemo na ponašanje druge strane. Naučno je dokazano da što se više smijemo drugi pozitivnije reaguju na nas. Međutim glasan smijeh prilikom poslovnog sastanaka o nama može dati negativan utisak npr. da smo nervozni i da nam je neugodna situacija, do toga da smo nekulturni i ne poštujemo širi auditorij. 4

Stoga je važno ukazati na jedan interesantan primjer komuniciranja prilikom poslovnog sastanka, naime prilikom sastanaka u jednoj korporaciji raspravljalo se o prijedlogu građevinskih investitora za uklanjanje drveća iz određene zone, na početku oko polovina prisutnih imala je ,prekrštene“ ruke da bi se taj broj povećao na $90 \%$ a kasnije i na $100 \%$ tako da su investitori u svom prijedlogu ostali usamljeni i bez podrške. Stoga se zaključuje da ako osoba ima ,prekrštene“ ruke sasvim je evidentno da se ne slaže sa onim što ste upravo izrekli, odnosno, osoba će prekstiti ruke na grudima onda kada se ne slaže sa onim što je čula. Sve dok neko drži ruke ,prekštene“ znači da ima negativan stav. Efikasan način da slušaoca natjerate da ne drži ruke na grudima jeste da

\footnotetext{
${ }^{4}$ Opširnije o problematici ,tihog jezika vremena i prostora“" vidjeti u: Edward T. Hall, The silent language, 1959., str. 13-50
} 
mu se da olovka ili brošura kako bi zauzeli otvoreniji stav tijela. Superioniji tip npr. odnos šefa i osoblja svoje ruke može ostaviti otvorene baš zbog toga da pokaže da se ne boji i zato ostavlja svoje ,tijelo i ruke ranjivim. ${ }^{\text {'5 }}$

Prilikom poslovne komunikacije potrebno je voditi računa o organizaciji vremena i prostora prilikom pripremanja poslovnog sastanka, dakle potrebno je koristiti „tihi jezik vremena i prostora“. Naime profesionalizam se ogleda u „držanju distance“ prilikom poslovnog razgovora te utvrđivanje vremenskog perioda za obavaljanje navedenog razgovora, dakle voditi računa o gore navedenim elementima. S druge strane prilikom poslovnog sastanka predmeti poput šolje, olovke, mogu poslužiti kao orjentacioni kriterij prilikom savladavanja navedenih aspekata. Naima ponuditi osvježenje tokom sastanka idealan je način da vidimo kako suprotna strana reagira na našu ponudu. Dakle, ako je osoba nesigurna i negativna u vezi onog što čuje, držat će šolju na suprotnoj strani tijela, a ako prihvata našu ponudu šolju će staviti blizu ruke kojom je uzima time ukazujući na pozitivan stav prema ponudi. ${ }^{6}$

U periodu poslije Drugog svjetskog rata, Amerikanci uslijed ekonomske ekspanzije počinju održavati ekonomske veze sa drugim dijelovima svijeta. Naime $u$ to vrijeme antropolozi se nalaze pred važnim zadatkom, dati odgovore na pitanja potencijalnih investitora: „Gdje mogu pročitati nešto što će mi pomoći da poslujemo s Arapima?“ Upravo gore navedeno pitanje i konstatacija govori u prilog činjenici koliko su kulturološke razlike zajedno sa ekonomijom i politikom važan aspekt poslovnog komuniciranja. Stoga je važno voditi računa o kulturološkim razlikama u bontonu prilikom pozdravljanja. Rukovanje i pozdravljanje, kao neverbalni element komunikacije, predstavlja prvi kontakt sa poslovnim partnerom i ostavlja važan utisak prilikom poslovnog sastanka i može bitno utjecati na daljnji tok pregovora. Naime Njemačke, Američke i Australijske kolege se pozdravljanju prilikom dolaska i opet prilikom odlaska sa sastanka. U Europskoj

\footnotetext{
${ }^{5}$ Opširnije vidjeti u: Alan i Barbara Piz, Vodič kroz govor tijela, 2005. godine, str.138-140

${ }^{6}$ Opširnije o problematici ,tihog jezika vremena i prostora“" vidjeti u: Edward T. Hall, The silent language, 1959., str. 13-50
} 
kulturi je evidentno pozdravljanje više puta $\mathrm{u}$ toku sastanka, a $\mathrm{u}$ Francuskoj kulturi, prema istraživanjima, oni provedu oko 30 minuta prilikom rukovanja. Indijske, Azijske i Arapaske kulture mogu da zadrže vašu ruku i nakon pozdravljanja. Na međunarodnim konferenacijama imamo širok dijapazon načina rukovanja te kulturoloških razlika prilikom korištenja gesta prihvatanja ili odbijanja ponude u čemu se ogleda i važnost navedenog neverbalnog elementa komunikacije. Po pitanju kulturnih razlika nailazimo i na gest klimanje glavnom što u većini kultura znači pristanak na ponudu, međutim kod Bugara ovaj gest označava „ne“ i Japanci ga koriste samo iz učtivosti, npr. kod Japanaca to bi zvučalo ovako: „Da u pravu ste ali ne slažem se s Vama." Stoga prilikom komunikacije sa Japancima, upravo zbog opisanih kulturoloških razlika treba voditi računa da se ne postavljanju pitanja čiji je odgovor „ne“ kao i da se često ne odgovara sa „ne“ upravo iz učtivosti jer je ,uglađen“ način komunikacije specifičan za njihovu kulturu, stoga umjesto odgovora „ne“" odgovor bi glasio:"Razmotrit ćemo ovaj prijedlog“" 7

\section{Komunikacijske strategije u poslovnoj komunikaciji}

Komunikacija je složen proces, stoga treba razviti dobru strategiju komuniciranja kako bi se postigli željeni rezultati, potrebno je vješto vladati sa elementima verbalne, neverbalne i posebno paraverbalne komunikacije. Ukoliko vješto vladamo navedenim elementima nećemo poslati poruku koju ne želimo u datom momentu. Navedena okolnost je posebno važna u poslovnoj komunikaciji da ne dođu u koliziju verbalna i neverbalna komunikacija. Dobro razvijenom strategijom smanjuje se broj prepreka u komunikaciji. Adekvatnim korištenjem komunikacijskih vještina, u poslovnom komuniciranju ostvaruje adekvatnu poslovnu strategiju koja se ogleda u stvaranju pozitivne radne atmosfere. $U$ tabeli ćemo prikazati tipologiju stategije

\footnotetext{
${ }^{7}$ Opširnije o problematici kulturoloških razlika i asocijativnih uzroka koji doprinose kulturološkim razlikama vidjeti u: Edward T. Hall, The silent language, 1959., str. 1375
} 
približavanja prema Bellu i Dalyu (npr. u poslovnoj hijerarhiji približavanje poslodavaca zaposlenicima) ${ }^{8}$

\section{Tipologija strategije približavanja prema Bellu i Dalyju ${ }^{9}$}

\begin{tabular}{|c|c|}
\hline 1. & $\begin{array}{l}\text { Altruizam: Osoba koja se nekom želi približiti pomaže ciljnoj } \\
\text { osobi, bez obzira na to čime se ona bavi. }\end{array}$ \\
\hline 2. & $\begin{array}{l}\text { Kontrola: Uvjeravatelj nastoji stvoriti dojam da kontrolira } \\
\text { ono što se trenutno događa. }\end{array}$ \\
\hline 3. & $\begin{array}{l}\text { Jednakost: Nastoji stvoriti dojam jednakog društvenog } \\
\text { položaja s osobom koja je cilj približavanja }\end{array}$ \\
\hline 4. & Opuštenost: Djeluje opušteno i ugodno. \\
\hline 5. & $\begin{array}{l}\text { Davanje kontrole: Dopušta ciljnoj osobi da preuzme kontrolu } \\
\text { nad odnosom. }\end{array}$ \\
\hline 6. & $\begin{array}{l}\text { Pridržavanje pravilima: Osoba koja se želi približiti pridržava } \\
\text { se pravila pristojne suradnje. }\end{array}$ \\
\hline 7. & Dinamičnost: Predstavlja se kao aktivna entuzijastična osoba \\
\hline 8. & $\begin{array}{l}\text { Poticanje otvaranja hvale se prinosi osobe kojoj se želi } \\
\text { približiti. }\end{array}$ \\
\hline 9. & Veselje: Maksimaliziranje pozitivnih aspekata komunikacije. \\
\hline 10. & $\begin{array}{l}\text { Uključivanje: Oduševljeno sudjelovanje u aktivnostima u } \\
\text { kojoj ciljna osoba uživa. }\end{array}$ \\
\hline 11. & $\begin{array}{l}\text { Bliskost: Ponašanja koja dovode do percepcije veće bliskosti } \\
\text { nego je to stvarno slučaj }\end{array}$ \\
\hline 12. & Slušanje: Aktivno i pažljivo praćenje izlaganja ciljne osobe. \\
\hline 13. & $\begin{array}{l}\text { Neverbalna blizina: Pokazivanje zanimanja upotrebom } \\
\text { različitih neverbalnih znakova. }\end{array}$ \\
\hline
\end{tabular}

${ }^{8}$ Opširnije o problematici interpesonalnog komuniciranja u različitim kontekstima vidjeti u: Kathleen K. Reardon, Interpersonalna komunikacija gdje se misli susreću, Alinea, Zagreb, 1998. godine, str. 164-175

${ }^{9}$ Kathleen K. Reardon, Interpersonalna komunikacija gdje se misli susreću, Alinea, Zagreb, 1998. godine, str. 182 
14. Optimizam: Osoba koja se želi približiti daje dojam da je pozitivna, optimistična ličnost.

15. Podrška: Davanje podrške ciljnoj osobi u društvenim situacijama.

Izvor: Bell, R.A. i Daly, J.A. (1984.). Funkcija približavanja u komunikaciji

Objavljeno uz dopuštenje Communication Monographs

\section{Vrste komunikacije}

\subsection{Verbalna komunikacija}

Verbalna komunikacija podrazumijeva prenošenje poruke od transmitera - odašiljača do recepcijenta - primaoca poruke putem komunikacijskog kanala. Verbalna komunikacija je razgovor kojim učesnici prenose svoje osjećaje, misli, saznanja i druge aspekte socijalne interakcije. U radnoj sredini, verbalna komunikacija je osnov za razmjenu poslovnih ideja i ponuda u čemu se ogleda i značaj verbalne komunikacije. Osnovni element verbalne pisane i usmene komunikacije je jezik u svojim pojavnim oblicima.

Jezik je nesumnjivo najvažniji sistem znakova koji se koristi u ljudskoj komunikaciji i koji se temelji na mogućoj velikoj kombinaciji što omogućava prenošenje velikog broja poruka. Znakovi su nastali kao konverzacija između forme (glas, pismo i izraz) i sadržaja te predstavljaju cjelinu. Sastoje se od signala i informacija vezano za signal, gdje signali služe kao sredstvo transporta informacija od pošiljaoca do primaoca. Skup znakova komunikacionog sistema usko je povezan s pravilima povezivanja za znakove, naziva se kod komunikacionog sistema. Sporazumijevanje pretpostavlja postojanje zajedničkog koda među osobama koje komuniciraju. To znači da se simboli u obliku znakova i znakovnih nizova riječi od kojih se jezik sastoji moraju koristiti i interpretirati na isti način, pri čemu su ključne tri dimenzije:

- $\quad$ Sintaksička dimenzija (odnos znakova, gramatike) 
- $\quad$ Semantička dimenzija (značenje znakova i znakovnih nizova, tj. odnos znakova i predmeta o kojem se komunicira)

- $\quad$ Pragmatička dimezija (korištenje znakova, odnos između znakova i korisnika, odnosno interpret znakova). ${ }^{10}$

\subsection{Neverbalna komunikacija}

Prilikom definiranja pojma neverbalne komunikacije javlja se problem jer većina teoretičara odvaja pojam verbalne komunikacije, koja podrazumijeva jezik odnosno govor, od neverbalne komunikacije koja podrazumijeva govor tijela. Naime, kako se vidi iz priloženog pojam verbalne i neverbalne komunikacije su suprotni, razilaze se u svom osnovnom značenju. Analizirajući više aspekata komunikacije, dolazi se do jedne univerzalne definicije koja u svom pojmu sadržava verbalnu komunikaciju (jezik/govor) i govor tijela-neverbalnu komunikaciju. U tom kontekst jezik/govor označavamo kao način prenošenja poruke, dakle jezik je osnovno sredstvo za prenošenje poruke, a govor tijela je pomoćno sredstvo za prenošenja poruke putem komunikacijskog kanala.

Odvajanje verbalnog od neverbalnog ponašanja $u$ dvije zasebne kategorije je praktično nemoguće. Kretanje i pokreti tijela obično uključuju: geste, pokrete tijela, izraze lica, pokrete očiju i držanje tijela. Glasovno ponašanje odnosi se na to kako je šta rečeno, a ne šta je rečeno. Opisuje niz neverbalnih znakova koji prate sam govor. Općenito se pravi razlika između dva tipa znakova:

1. Glasovne varijacije koje proizvode glasnice tokom govora, a ovise o promjenama u visini, trajanju glanoći i šutnji

2. Glasovi koji su primarno rezultat drugih fizioloških mehanizama, osim samim glasnicama npr. ždrijelo usne i usna šupljina. ${ }^{11}$

\footnotetext{
${ }^{10}$ Opširnije vidjeti u: Opširnije vidjeti u: Miloš Babić, Uvod u medije i komunikacije, Banja Luka/Travnik, 2015, str.21-23

${ }^{11}$ Opširnije vidjeti u: Mark L. Knapp, Judith A. Hall, Neverbalna komunikacija u ljudskoj interakciji, Naklada Slap, 2010., strana 5-10.
} 
Neverbalna komunikacija je važan dio komunikacijskog procesa, mada većina teoretičara ističe verbalnu komunikaciju jer je ona sama po sebi sporazumijevanje, a pritom zanemaruju neverbalnu komunikaciju kao nešto sporedno. Naime, ukoliko dođe u koliziju verbalna sa neverbalnom komunikacijom, postoji velika vjerojatnoća da ćemo sagovorniku poslati poruku koju ne želimo. Stoga se komunikologija kao nauka čiji je predmet proučavanja način na koji ljudi šalju poruke jedni drugima naziva naukom budućnosti jer vladanje svojim govorom tijela, dakle usklađivanje verbalne sa neverbalnom komunikacijom važna je u svim poslovima posebno menadžerskim, prosvjetnim, advokatskim i drugim poslovima gdje je komunikacija osnovni element.

O samom značaju neverbalne komunikacije govori i podatak da je ona širi pojam od govora tijela i uglavnom podržava verbalnu komunikaciju. Ljudi više vjeruju akcijama nego riječima što potvrđuje i jedno istraživanje koje pokazuje 55\% utisaka ostavljaju izrazi lica, $38 \%$ neverbalni aspekti (parajezik) i 7\%, odnosno ono što je rečeno. Neverbalna komunikacija ima višestruku funkciju:

- $\quad$ Koristi se da bi naglasila verbalnu poruku

- $\quad$ Dopunjuje verbalnu poruku, ali može biti i kontradiktorna s njom

- Reguliše interakcije

- $\quad$ Može biti zamjena za verbalnu poruku ${ }^{12}$

Način i forma neverbalne komunikacije npr. držanje tijela razlikuje se u pojedinim tradicijama, kulturama i državama. Kao primjer navodimo neverbalnu komunikaciju prilikom sjedenja, npr. prekrštene noge, ova forma neverbalne komunikacije u pojednim kulturama označava nepoštovanja sagovornika dok u našoj sredini takav oblik držanja tijela predstavlja jednu normalnu pojavu.

Dakle, gore opisani primjer predstavlja jednu normalnu okolnost koja može negativno utjecati u poslovnoj komunukaciji jer druga strana očekuje da smo upoznati sa njenom tradicijom i kulturom posebno ako

12 Opširnije vidjeti u: Miloš Babić, Uvod u medije i komunikacije, Banja Luka/Travnik, 2015, str.24 
se radi o poziciji gdje nam je osoba nadređena i navedeni potez može shvatiti kao nepoštovanje jer očekuje da smo upoznati sa aspketima kulturoloških razlika. Upravo poznavanje neverbalne komunikacije u pojednim kulturama važno je kod sklapanja poslova sa međunarodnim elementom jer psihološki gledano može pozitivno utjecati na pregovarače posebno u menadžerskim poslovima.

Navedni faktor važan je prilikom sklapanja poslova u multinacionalnim korporacijama gdje se susreću različite kulture, tradicije itd. Stoga se komunikologija označava kao nauka budućnosti u domenu humanističkih nauka i postaje važan faktor kod oblikovanja poslovnog ambijenta gdje zaposlenici trebaju proći seminar za vladanje verbalnom, neverbalnom i paraverbalnom komunikacijom. Naime, početkom XX stoljeća, komunikologija je dobila na važnosti posebno u političkim krugovima prilikom pripremanja predizbornih kampanja posebno u debatama, npr. SAD, gdje se jasno vidi na koji način kandidati vladaju vješinama verbalne, neverbalne i paraverbalne komunikacije. Navedena okolnost posebno je značajna kod prevazilaženja kulturoloških razlika prilikom rukovanja i pozdravljanja te gesta npr.klimanja glavom što u nekim kulturama označava prihvatanje a u nekim kulturama označava odbijanje ponude.

Osim što $\mathrm{u}$ konverzaciji upravljaju svojim verbalnim izjavama komunikatori to čine i svojim neverbalnim ponašanjem: izrazi lica, tjelesni pokreti, kontakt očima, udaljenost na kojoj se govori i konverzacijski regulator, kao što su klimanje glavom, sve to doprinosi dojmovima što ih komunikatori stiču jedni o drugima odnosima te o sadržaju poruke. Prema Burgoonovoj neverbalna su ponašanja ponekad važnija, jer se neverbalnim znakovima ponekad više vjeruje nego verbalnim posebno kad su u suprotnosti sa verbalnim. Teoretičarka navodi niz studija iz kojih je vidljivo da se, interpretirajući poruke, odrasle osobe više oslanjaju na neverbalne nego na verbalne znakove. ${ }^{13}$

${ }^{13}$ Opširnije o problematici neverbalnog upravljanja konverzacijom te utjecajima neverbalnog ponašanja na konverzaciju vidjeti u: Kathleen $K$. Reardon, Interpersonalna komunikacija gdje se misli susreću, Alinea, Zgreb, 1998. godine, str. 101 


\subsection{Praverbalna komunikacija}

Paraverbalna komunikacija podrazumijeva brzinu, jačinu glasa, dakle način na koji izgovaramo riječi. Paraverbalnom komunikacijom sagovorniku šaljemo poruku bez obzira na značenje izgovorenih riječi. Snažan osjećaj netrepeljivosti, uzbuđenosti u našem govoru daju posebne karakteristike kojim recepcijent više vjeruju više nego verbalnim porukama.

Istraživanja su pokazala da paraverbalnoj komunikaciji pripada čak 38\% ukupne komunikacije. Vještina paraverbalne komunikacije važan je faktor u komunikaciji menadžera, voditelja projekata, poslovnih sekretarica i svih zaposlenih koji u svom radu svakodnevno komuniciraju i dolaze u kontakt sa saradnicima, kolegama i poslovnim partnerima bilo direktno, bilo telefonskim ili elektronskim putem. Konstatujemo da vokalni znakovi imaju nadmoć pri formiranju stajališta kada su vokalni i verbalni sadržaji u kontradiktornosti. ${ }^{14}$

Dobar narator (lat. narrator-govornik, onaj koji pripovijeda) ton glasa koristi kako bi sagovorniku eksplicitno skrenuo pažnju na određene detalje u komunikaciji, odnosno povišenim tonom stavlja naglasak na važnije komponente komunikacijskog procesa. S druge strane, dobar sagovornik koristi ton glasa kako bi spriječio eskaliranje konfliktnih situacija posebno u radnoj sredini.

\subsubsection{Paralingvistička sredstva}

Najvažnije paralingvističko sredstvo je glas, putem glasa šalje se ,jaka poruka“" o stanju naše svijesti, dakle ljutnja, srdžba, sreća itd. Osnovni elementi glasa su: boja, jačina, brzina $i$ ton. Razlikujemo paralingvistička sredstva koja se odnose na ekspresivnu dimenziju govornog znaka i nosioci su poruke, npr. smijeh, plač, drugu grupu čine

\footnotetext{
${ }^{14}$ Opširnije o problematici utjecaja vokalnih znakova koji prate izgovorene riječe u paraverbalnoj komunikaciji vidjeti u: Mark L. Knapp, Judith A. Hall, Neverbalna komunikacija u ljudskoj interakciji, Naklada Slap, 2010., strana 56-57
} 
sredstva koja spadaju u impresivnu dimenziju govornog znaka, dakle govornikov stav prema informaciji koju iznosi. ${ }^{15}$

Jačina glasa sama po sebi ima više odrednica, npr. previše tih govor ukazuje na intimnost $\mathrm{u}$ interpersonalnoj komunikaciji, previše visok ton ukazuje na konflikntu situaciju. U radnoj sredini potrebno je uskladiti jačinu glasa prema situaciji, koristiti jačinu koja je dovoljna da bi se izgovoreno adekvatno shvatilo. Gubljenje zraka, podrhtavanje glasa prilikom komunikacije ukazuje na strah i uzbuđenje i nije poželjan faktor u profesionalnoj komunikaciji jer ukazuje na nedostatak samopouzdanja. U paralingvistička sredstva ubrajamo i stanku koja podrazumijeva odsustvo vokalnih znakova. ${ }^{16}$

Većina nas mijenja jačinu glasa kada želimo naglasiti određeni dio poruke. Prozodija je riječ kojom se opisuju sve varijacije u glasu koje prate govor, a pomažu u prijenosu značenja izgovorenog. U dolje navedenom primjeru ukazuje se na vokalne naglaske koji utječu na interpretaciju sljedećih poruka:

1. On je posudio ovaj kompjuter radnoj kolegici. (On je posudio kompjuter i niko drugi.)

2. On je posudio ovaj kompjuter radnoj kolegici. (On je posudio ovaj kompjuter radnoj kolegici nije prodao.)

3. On je posudio ovaj kompjuter radnoj kolegici. ( On je posudio ovaj kompjuter radnoj kolegici, a ne neki drugi.)

4. On je posudio ovaj kompjuter radnoj kolegici. (On je posudio ovaj kompjuter radnoj kolegici a ne nekoj drugoj osobi.

Često manipuliramo visinom glasa da bismo pokazali kraj izjavne rečenice (snižavanjem glasa) ili pitanja (podizanje glasa). Kad svjesno manipuliramo našim tonom tako da vokalna poruka proturječi verbalnoj, kao kod sarkazma, naprimjer možete reći „odlično se

${ }^{15}$ Opširnije o problematici utjecaja vokalnih znakova koji prate izgovorene riječe u paraverbalnoj komunikaciji vidjeti u: Mark L. Knapp, Judith A. Hall, Neverbalna komunikacija u ljudskoj interakciji, Naklada Slap, 2010., strana 57

${ }^{16}$ Opširnije o problematici utjecaja vokalnih znakova koji prate izgovorene riječe u paraverbalnoj komunikaciji vidjeti u: Mark L. Knapp, Judith A. Hall, Neverbalna komunikacija u ljudskoj interakciji, Naklada Slap, 2010., strana 56-57 
zabavljam“ tako da zvuči „Grozno mi je“. Ako su vas doživjeli sarkastično, vokalni znakovi u poruci vjerojatno su istisnuli verbalne. ${ }^{17}$

\section{ZAKLJUČAK}

Na temelju iznesenog, zaključujemo da je komunikacija proces u kojem je potrebno vješto vladati verbalnim, neverbalnim i posebno paraverbalnim elementima komunikacije. U govorničkim profesijama (advokat, menadžer, sekretar, profesor) najvažniji momenat je slaganje verbalnih, neverbalnih i paraverbalnih komponenti, svako odstupanje od navednog može dovesti do konfliktnih situacija. $U$ radu je prikazan način prevladavanja prepreka u komunikaciji kao i načini sinhroniziranja verbalnih, neverbalnih i paraverbalnih komponenti prilikom komuniciranja u radnoj atmosferi sa posebnim naglaskom na paralingvističke elemente i adekvatno korištenje istih. Naime, u svrhu prevazilaženja prepreka u koumunikaciji, pro futuro - ubuduće potrebno je na nivou svake institucije periodično organizirati seminare, edukacije i obuku u svrhu adekvatnog korištenja komunikacijskih vještina dakle sinhroniziranje navedenih elemenata kao i prevazilaženje kulturoloških razlika među investitorima iz različitih dijelova svijeta $u$ svrhu stvaranju pozitivne radne atmosfere, što je već duži niz godina i praksa u velikim multinacionalnim korporacijama.

\section{Literatura:}

1. Edward T. Hall, The silent language, 1959

2. Miloš Babić, Uvod u medije i komunikacije, Banja Luka/Travnik, 2015

3. Mark L. Knapp, Judith A. Hall, Neverbalna komunikacija u ljudskoj interakciji, Naklada Slap, 2010

4. Kathleen K. Reardon, Interpersonalna komunikacija gdje se misli susreću, Alinea, Zagreb, 1998. Godine

5. Sean Neill, Neverbalna komunikacija u razredu, Educa,Zgreb, 1991.

6. Tijana Mandić, Komunikologija (psihologija komunikacije), Beograd, 2003

${ }^{17}$ Opširnije o problematici utjecaja vokalnih znakova koji prate izgovorene riječe u paraverbalnoj komunikaciji vidjeti u: Mark L. Knapp, Judith A. Hall, Neverbalna komunikacija u ljudskoj interakciji, Naklada Slap, 2010., strana 58 
7. Brajša, P.: Pedagoška komunikacija, 2. prošireno izdanje, Školske novine, Zagreb, 1994.

8. Joseph Turow, Mediji danas - Uvod u masovne komunikacije, Clio, Beograd, 2013.

9. Alan i Barbara Piz, Vodič kroz govor tijela, 2005. godine

10. Dodatna literatura:

11. D. Katunarić: Carstvo medija: Zbornik tekstova. Litteris, Zagreb

12. Bagarić, Ž., Banović, D., Đurković, M., Gelo, N., Nedić, S.,.Komunikacija, nastavni materijali, Osijek: Ekonomski fakultet u Osijeku, 2011.

13. Sandra Milenković i Kristina Delić, Komunikologija i poslovna Komunikacija, Beograd, 2011

14. Bakić-Tomić, Lj., Globočnik Žunac, A., Kožić, D. , Neverbalni komunikacijski kanali u nastavi, Hrvatski časopis za odgoj i obrazovanje broj 15, 2013

15. McNeill, D. (Ed.). Language and gesture. New York: Cambridge University Press, (2000)

16. Roth, Winfried. Priručnik semiotike. Zagreb : CERES, 2004.

17. Rijavec, M. i Miljković, D. Neverbalna komunikacija - Jezik koji svi govorimo.

18. Zagreb : IEP, 2002.

19. Morris, D. Peoplewatching - Guide to the body language. London : Vintage Books, 2002.

20. Lamza-Maronić, M. i Glavaš, J. Poslovno komuniciranje. Osijek : Studio HS Internet, 2008.

21. Miletić, N. Fenomenologija neverbalne komunikacije u funkciji kulturne produkcije, Liburna. lipanj 2012

22. Škarić, I.Temeljci suvremenoga govorništva. Zagreb : Školska knjiga, 2000.

23. Wetherbe, J.C. i Wetherbe, B. Vještine komuniciranja, Dakle, u čemu je stvar? Ljubljana : Orbis, 2005.

24. Tafra-Vlahović, M. Javni govor. Zagreb : Visoka škola za poslovanje i upravljanje "Baltazar Adam Krĉelić", 2013. 
Hatidze Burnic, PhD

Original scientific article

Anita Mujkic, B.A.

University of Bihac

Islamic Pedagogical Faculty

\section{VERBAL, NON-VERBAL AND PARAVERBAL COMMUNICATION IN THE WORKING PLACE}

\section{Abstract}

This work describes aspects of verbal, non - verbal and paraverbal communication, displays classification of non - verbal communication and paralinguistic means and non - verbal signs which are its composing part. After describing categories of the non - verbal communication and its components comes a review of verbal, non - verbal and paraverbal communication in a workplace and the importance of adequate use of the elements of a communication process. Furthermore, after describing categories of non verbal communication and its components comes a review of paraverbal communication in a workplace.

Keywords: communication, non - verbal, verbal, paraverbal communication, paralinguistic means 


$$
\begin{aligned}
& \text { المدرسة الدكتورة خديجة بورنيتش } \\
& \text { جامعاة بيهاتش } \\
& \text { كلية التربية الإسلامية } \\
& \text { hatidze_b@hotmail.com } \\
& \text { المعيدة آنيتا مويكيتش } \\
& \text { جامعة بيهاتش } \\
& \text { كلية التربية الإسلامية } \\
& \text { anita_ramulic@yahoo.com }
\end{aligned}
$$

العلاقة بين الاتصال اللفظي وغير اللفظي والاتصهال ما وراء الكلام في بيئة العمل

\section{الخلاصية}

في هذا البحث سيتم عرض المزايا الأسـاسية للاتصال اللفظي وغير اللفظي والاتصال

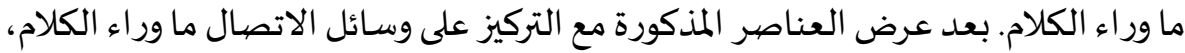

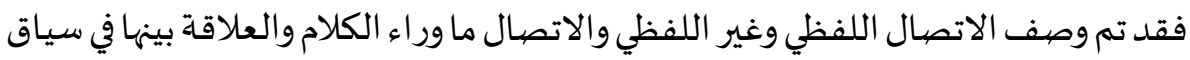
جو العمل وأهمية استخدام مناسب للعناصر المذكورة في العملية الاتصالية.

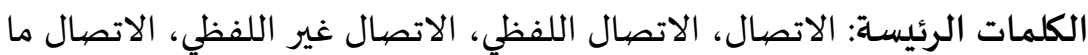

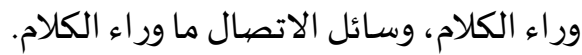

